\title{
Maria Natalina Jardim: nem tudo são flores
}

\author{
Maria Inês de Moraes Marreco \\ Doutoranda em Literatura Brasileira / UFMG
}

\begin{abstract}
RESUMO
Este texto tem como objetivo, ao entretecer a vida e a obra da escritora Maria Natalina Jardim, apresentar aspectos da luta que a mulher de sua época, muitas vezes, tinha que travar para ter acesso à vida profissional, mesmo quando era qualificada para tal.
\end{abstract}

\section{PALAVRAS-CHAVE}

Mulher, profissão, família, luta, objetivo

Maria Natalina Jardim de Almeida, professora, poeta, contista, cronista, romancista, ensaísta e pintora, nasceu no dia 25 de dezembro, daí o nome Natalina, em Matias Barbosa, “a um grito de Juiz de Fora”, como define a escritora, em Minas Gerais.

A oitava dos quinze filhos de Franklin Rodrigues de Moraes Jardim e de Maria Cassemira Magalhães Jardim (Pequita), Natalina viveu até os 6 anos de idade em Juiz de Fora. Morou com a família em Uberaba, Minas Gerais, até agosto de 1921, quando se mudou para Uberabinha, hoje Uberlândia, também nesse estado. Formou-se em professora pela Escola Normal de $2^{\circ}$ Grau de Uberlândia, em 1928. Nessa ocasião o pai de Natalina fora transferido para Araguari, Minas Gerais, grande foco político. Pelo fato de ser gerente do extinto Banco de Crédito Real, foi oferecido a ela uma cadeira no grupo escolar da cidade. Entretanto, nessa ocasião a preferência política da população local se dividia entre dois partidos políticos cujas divergências os tornavam ferrenhos inimigos, e o convite para que a jovem professora ocupasse tal espaço partira de ambos os partidos, podendo-se inferir que o objetivo era agradar o novo gerente do Banco. Para não se comprometer, seu pai aconselhou-a seguir os passos da irmã, que já exercia o magistério em Tupaciguara, perto de Araguari. O fato de já residir há algum tempo naquela localidade tornara-a respeitada, facilitando, assim, a adaptação da irmã. Entre seus primeiros alunos no Grupo Escolar de Tupaciguara, no 
Triângulo Mineiro, estava Rondon Pacheco, futuro Governador de Minas Gerais durante o regime militar. Maria Natalina casou-se no dia 30 de março de 1932 com João Bronzo de Almeida, com quem teve seis filhos e hoje, onze netos. Após o casamento ela e o marido mudaram-se para Araguari. Foi então que o pai, receando que a filha trocasse a profissão pelo casamento, convenceu-a a fundar um colégio:

- Minha filha, você é muito habilitada, já deu provas disso. Não desperdice sua vocação e o tempo. Monte um colégio com todas as exigências necessárias para merecer um bom nome e a confiança das principais famílias de Araguari. Mas faça-o com gosto, impondo um certo rigor e até mesmo um certo luxo nas instalações e no uniforme dos alunos. Cerque-se de boas auxiliares, redija um bom regulamento. Tenho a certeza de que você vai se sair muito bem nessa iniciativa e que o seu colégio irá preencher a falta que a cidade está sentindo de um colégio à altura das famílias da cidade. ${ }^{1}$

Seguindo o conselho paterno, a jovem professora inaugurou o Colégio Infantil Santa Terezinha em 1933. Conta a mestra:

Dirigir o colégio foi um grande aprendizado para mim, não só como diretora, mas também como comunicadora, instrutora, professora e gestora de finanças. Foi quando abri minha primeira conta bancária. Recebia, pagava, redigia atas e comunicava-me com os órgãos da administração estadual da educação. Depois de várias visitas dos fiscais de ensino, o colégio foi registrado. Obtido o registro, meus alunos já recebiam os seus diplomas do próprio estabelecimento, o que lhes dava o direito de se matricularem em qualquer escola de segundo grau. Antes, eles se submetiam aos exames no Grupo Escolar, para receberem o diploma do curso primário. ${ }^{2}$

Mas, para atingir as metas a que se propusera, como dirigir um colégio, além de ser professora e gestora das finanças, teve também que desenvolver sua capacidade de comunicação. Naquele tempo, mesmo quando a sociedade permitia que a mulher trabalhasse fora do lar, não lhe era permitido negligenciar as tarefas domésticas. Com Natalina o processo não foi diferente, tinha tanto que dar conta das responsabilidades inerentes à direção da escola, quando da administração da casa e da vida familiar. A princípio, o marido "tolerava” pacientemente o entra e sai de alunos, os questionamentos sobre o funcionamento interno da escola, enfim, o movimento inerente de uma instituição cultural. Mas uma coisa era necessária, que a casa estivesse em ordem. No momento em que qualquer problema surgia, ou a filha adoecia, a tolerância do companheiro se esgotava.

Em 1936, o marido de Natalina, João Bronzo, foi transferido para Belo Horizonte. Nesse período, o colégio já se tornara um próspero e reconhecido estabelecimento de ensino,

\footnotetext{
${ }^{1}$ JARDIM. De lá pra cá: minha família e eu, p. 91

2 JARDIM. De lá pra cá: minha família e eu, p. 92.
} 
mas Maria Natalina teve que abdicar da vida profissional para se dedicar somente ao marido e filhos. Em 1946 a família mudou-se para Barbacena, onde residiram até 1956, quando voltaram em definitivo para Belo Horizonte.

No período em que morou em Barbacena, Natalina montou no porão de sua casa uma pequena farmácia para distribuição de remédios aos pobres e fez o projeto da construção de uma casa para abrigar mães solteiras, que mais tarde foi ampliado para ser também uma casa para idosos, e que ainda hoje funciona com o nome de Vila Sant'Ana.

Nas palavras de John Stuart Mill, “o domínio dos homens sobre as mulheres é diferente de todos os outros porque não é imposto pela força: é aceito voluntariamente, e as mulheres não só não se queixam como são co-responsáveis por nele consentirem”. ${ }^{3}$ Ainda que haja uma corresponsabilidade no consentimento desse domínio, é preciso levar em consideração as circunstâncias em que tal consentimento foi arbitrado. Nem sempre era dado às mulheres a chance de se fazer ouvir. $O$ que não significa que elas aceitassem resignadamente a todas as regras que lhe eram impostas. Sempre existiu e existirão aquelas que não aceitam as imposições da sociedade patriarcal. Desde que as mulheres conheceram meios para exteriorizar seus sentimentos pela escrita, os registros da sua insatisfação têm aumentado. Cada dia mais notável é o número de mulheres que reivindicam direitos como, por exemplo, a uma educação melhor, com a mesma qualidade e nas mesmas áreas de conhecimento que a dos homens; reivindicam ainda a admissão em profissões e atividades que até então lhes eram vedadas, enfim, de conquistar espaços que lhes eram proibidos.

Não é esse o caso de Maria Natalina. Ela soube equilibrar as funções de mãe, dona de casa, profissional e, sobretudo, não deixar ofuscar sua luz de "mulher à frente do seu tempo".

Seu primeiro poema, "Espinhos”, que foi inspirado pela observação da frequência com que os poetas falavam da rosa e da escassez com que se referenciavam aos espinhos, os protetores da “dama indefesa”, já traz à tona a sensibilidade da escritora. Sua estreia na literatura se deu com Rosa menina, ${ }^{4}$ uma coletânea de contos, crônicas e poesias, publicada em 1982. Mauro Mendes Vilella, no "Prefácio", ressaltou serem seus relatos "perfis e lembranças que não se apagam”, isto é, rememorações saudosas e saudáveis, guiadas pelo real sem deixar de lado a imaginação.

Nessa obra, contos, crônicas e cartas dividem o espaço com as poesias, ponto forte na literatura de Maria Natalina. Em “O Cristo que eu pintei”, a escritora, através da voz do

\footnotetext{
${ }^{3}$ MILL. A sujeição das mulheres, p. 56.

${ }^{4}$ JARDIM. Rosa menina. Prefácio, p.11-12.
} 
Cristo, deixa transparecer sua própria voz: “ - Minha cabeça não deite para o chão! / Procure erguê-la, voltada para a frente; / demonstro a todos que nada foi em vão, / quando meu sangue quis dar por minha gente.”5 Assim como a de Cristo, sua vida também não foi em vão; lutou não só pela educação dos filhos, como também o fez pela educação de muitas outras crianças; desempenhou seu papel de esposa e mãe com carinho, equilíbrio e responsabilidade, e se, às vezes, teve que ceder, o fez por sua gente. Em suas poesias, “Desabafo” demonstra que nem sempre a segurança a acompanhava: "Perante esta platéia, aponto o meu fracasso,/ embora isto me custe esforço sobre-humano.”6 Ou em "Lamento”, quando perde o marido e, tomada pela imensa tristeza tantas vezes, tem que fingir alegria: "Meu ar de festa é pura fantasia. /Não é sincero, é falso o meu sorriso"; 7 ainda em “Anseios”, quer ”... subir pelo espaço, sem medo, (...) voar, como faz a andorinha”, ${ }^{8}$ homenageia o companheiro que se foi tão cedo, os filhos, a natureza, fala dos seus sonhos e, principalmente, dos seus medos: do escuro, do futuro, do agora, do fim. E, com sabedoria, entre perguntas e respostas, aborda a grande questão da existência em “Talvez”, poesia permeada das milhares de interrogações que permeiam a vida de todos nós.

Em 1994, veio a público Jerônimo, que relata, de forma romanceada, um caso de amor frustrado da década de 1870. Nessa narrativa, de cunho memorialístico, pode-se inferir que algumas passagens dolorosas narradas no livro atingiram o pai da autora, fazendo-o sofrer por toda a vida pelo preconceito de ser bastardo. Jerônimo era filho natural de Maria Antônia Cortes Saraiva e de Antônio Augusto Cunha, que se casou com Amanda, moça de rara beleza e filha de um homem rico, dono de diversas fazendas. Ao revelar para a noiva a existência do filho, ouviu dela: “- Que importância tem isso, meu querido? Louvo sua franqueza e ainda mais o admiro pelo seu gesto tão digno. Digo-lhe mais: faço questão que o traga para morar conosco, assim que a idade dele permitir." "9 Mas as coisas não se passaram como esperava o Dr. Cunha. Sua mulher transformou a vida do pequeno Jerônimo num pesadelo, marcando-o para sempre com a pecha de filho bastardo.

Em 1999, a escritora publicou No mar da vida, livro de poesias, sonetos e versos livres, e em 2006, Perdas e danos: (um escritor conta a sua história) Jorge de Freitas, no

\footnotetext{
${ }^{5}$ JARDIM. Rosa menina, p. 95.

${ }^{6}$ JARDIM. Rosa menina, p. 97.

${ }^{7}$ JARDIM. Rosa menina, p. 99.

${ }^{8}$ JARDIM. Rosa menina, p. 101.

${ }^{9}$ JARDIM. Jerônimo, p.34.
} 
qual o narrador é também personagem, enriquecendo a narrativa com o entretecimento de ficção e realidade. Nessa obra Maria Natalina conta a história de sua irmã Maria Helena Jardim, pediatra mineira nascida em 1916. Na trama, Jorge de Freitas, escritor principiante, narra como sua história pessoal se perde e se desfaz na trajetória profissional da médica. Em 2007, Maria Natalina Jardim publicou Flores das 4 estações, e em 2010, Minha poesia minha tela, uma mistura de belas poesias e dos últimos quadros que pintou. Pronto para ser publicado, encontra-se o livro de memórias De lá pra cá: minha família e eu.

Além desses livros, Natalina tem trabalhos publicados em várias antologias, em revistas do Instituto Histórico e Geográfico de Minas Gerais, da Academia Mineira de Letras, da Academia Feminina Mineira de Letras. Seu nome tornou-se verbete na Enciclopédia de Literatura Brasileira, de Afrânio Coutinho e Galante de Souza, no Dicionário de poetas contemporâneos, de Francisco Igreja, e no Dicionário de mulheres escritoras, de Hilda Agnes Hübner Flores.

Outro fato de destaque na vida da escritora é, segundo ela, em entrevista a mim concedida, sua “veia jornalística”. Maria Natalina fundou, em 1935 o jornal O Collegial (Orgam mensal do Collegio Santa Terezinha), em Araguarí. Em 1936, em função da transferência do marido de Natalina para outra cidade e, consequentemente, a mudança da família, a direção do jornal passou para Niva Camarano. Os redatores eram os próprios alunos do colégio, que publicavam suas redações (na época, chamadas composições), cartas, notas sociais, artigos sobre cultura geral, charadas, e até uma coluna de piadas, denominadas “Anedoctas”. De um exemplar desse jornal, já amarelecido e impossível de se ver a data completa, apenas o ano de 1935, vale registrar:

\section{ENTRE MARIDO E MULHER}

-A nossa filha completou a sua educação - diz a esposa - A Mathilde sabe pintar, dançar, montar a cavallo e tocar piano. É chegada a ocasião de a casarmos.

- Tens razão - responde o esposo - preciso arranjar-lhe um marido que saiba cosinhar e dar pontos nas meias...

Cabe-nos ressaltar nesse fragmento a importância das "prendas domésticas” naquela época. Apesar de aparentemente culta e capaz de se enquadrar nos moldes de seu tempo, Mathilde não sabia cozinhar nem costurar, tornando-a uma moça sem dotes especiais para o casamento. A ironia do pai ao exigir que tais qualidades deveriam ser procuradas no noivo denota, claramente, a função e o lugar da mulher na sociedade vigente. 
Em 1986 Maria Natalina fundou Notas Acadêmicas, informativo da Academia Feminina Mineira de Letras - AFEMIL. No primeiro editorial ela assim escreveu:

Um dos meios de comunicação indispensável ao bom andamento de uma organização é, a meu ver, um jornal, mesmo de pequena aparência, como será o nosso. Por isso estamos aqui.

De tiragem mensal, cuidar de transmitir às acadêmicas tudo o que se relaciona com a nossa entidade, quer seja no campo da cultura, como no campo social. Publicar os trabalhos aqui apresentados pelas sócias, estimulando, aplaudindo, além de dar outras notícias interessantes. Assim, ao invés da omissão, passaremos para um trabalho construtivo, no intuito de elevar o conceito da AFEMIL e de colaborar para o progresso cultural do nosso Estado. ${ }^{10}$

A veia jornalística de Maria Natalina Jardim continua a pulsar. A escritora tem colaborado com artigos no Estado de Minas, caderno “Opinião”, desde novembro de 1988, Jornal de Paraopeba, Jornal de Minas, coluna “Destaque”, e Vozes do Sion. Também publica pela internet no link http:// sites.uol.com.br/natalinajardim.

Maria Natalina Jardim é fundadora e membro efetivo da Academia Feminina Mineira de Letras; pertence ao Instituto Histórico e Geográfico, à Academia Municipalista de Letras de Minas Gerais, à UBT - União Brasileira de Trovadores, seção Belo horizonte, e sócia correspondente da União Brasileira de Escritores - UBE - seção Rio de Janeiro. Recebeu inúmeros prêmios em concursos, menções honrosas e diplomas de entidades culturais.

Apesar de extenso, transcrevo as palavras com as quais a escritora se define:

Todos somos arremedos de poetas aos dezoito ou vinte anos, quando os sentimentos afloram do imenso aglomerado de que é feita a alma humana. É a época das paixões e desenganos. Em alguns, esses impulsos vigoram, se estendem e permanecem. Em outros, fenecem, afogados pelas primeiras desilusões e a vida corre sem grandes emoções. Os que têm, de fato, o dom da poesia, creditam-no na palavra, esse bem universal que nasce de nós mesmos. E como a palavra é susceptível de aprimoramento, podemos trabalhar com ela até a perfeição. Na verdade, o homem já nasce poeta, músico ou pintor, mas a cultura aperfeiçoa-lhe o dom, seja da palavra, seja o dom sonoro, seja da escultura ou das formas. Assim eu, amante da palavra que sou, impulsionada pelos sentimentos de perda, vi surgirem meus primeiros versos na forma de lamento, suspiros doridos, produtos da solidão. Tratei de aproveitar o dom que desconhecia. À procura de lenitivo, atentei para a lua, o sol, as estrelas, o mar, os rios, os pássaros e as flores. Fui acometida de sentimentos até então encobertos, visto colocar sempre em primeiro plano os cuidados maternais e a responsabilidade doméstica. Por força atávica, inicieime nos sonetos. Depois, sem filiação a qualquer escola, influenciei-me pela poesia moderna e passei a fazer meus versos soltos, rimados ou

\footnotetext{
${ }^{10}$ NOTAS ACADÊMICAS, Ano I, n. 1. Inédito.
} 
não, deixando aflorar meus medos, minhas angústias e anseios, minha força e minha fé, na procura de mim mesma. (...) A tela veio depois do poema. Continuando, atrevi-me na prosa e publiquei meu primeiro livro Rosa menina, de contos, crônicas e poesias. Passei a ler nossos melhores escritores, inclusive nossas melhores escritoras, passei por autores estrangeiros antigos e contemporâneos, cada vez mais tomei gosto pela leitura. Sinto que comecei tarde, mesmo tendo encontrado, ao me casar, uma escolhida biblioteca adquirida por meu companheiro, amante da boa leitura e possuidor de considerável cultura geral. Ao longo do tempo, publiquei outros livros, em épocas diversas. ${ }^{11}$

Sensibilizada, pois, pelas palavras dessa escritora, que, embora em muitas ocasiões se mostre tímida, em outras, é o protótipo da mulher corajosa e guerreira, gostaria de chamar a atenção para uma questão que se reveste da maior importância: a de dar visibilidade e liberdade às mulheres em quaisquer que sejam as posições por que elas optarem, quer seja na vida privada, quer seja na vida pública. Que lhes seja possível escolher livremente o que lhes possa interessar, que não sejam impedidas por nenhum constrangimento legal de tomarem direções variadas.

Encerro, assim, este texto, recorrendo a John Stuart Mill, quando afirma: “Já não se trata, pois, de questionar se a igualdade da mulher na vida pública a levou até onde deveria. Trata-se, sim, de reiterar que a sua igualdade a levará tão longe quanto ela quiser ir.”12

\begin{abstract}
This paper aims, by interweaving the life and work of writer Maria Natalina Jardim, to present aspects of the challenges a woman of her time had to face to have access to professional life, even when she was sufficiently qualified to do so.
\end{abstract}

\title{
KEYWORDS
}

Women, work, family, challenges, goals

\footnotetext{
11 JARDIM. De lá pra cá: minha família e eu, p.124.

${ }^{12}$ MILL. A sujeição das mulheres, p. 31.
} 


\section{REFERÊNCIAS}

JARDIM, Maria Natalina. Rosa menina. Belo Horizonte; Imprensa Oficial, 1982.

JARDIM, Maria Natalina. Jerônimo. Belo Horizonte: O Lutador, 1994.

JARDIM, Maria Natalina. Perdas e danos (um escritor conta a sua história) Jorge de Freitas.

2. ed. Belo Horizonte: Imprensa Oficial, 2007a.

JARDIM, Maria Natalina. Flores das 4 estações. Editora do Autor, 2007b.

JARDIM, Maria Natalina. Minha poesia minha tela. Belo Horizonte: O Lutador, 2010.

JARDIM, Maria Natalina. De lá pra cá: minha família e eu. Inédito.

MILL, John Stuart. A sujeição das mulheres. Coimbra: Almedina, 2006. 